\title{
A Nanoscale Record of Impact-Induced Pb Mobility in Lunar Zircon
}

Tyler B. Blum ${ }^{1 *}$, David A. Reinhard ${ }^{2}$, Matthew A. Coble ${ }^{3}$, Michael J. Spicuzza ${ }^{1}$, Yimeng Chen $^{2}$, Aaron J. Cavosie ${ }^{4}$, Lutz Nasdala ${ }^{5}$, Chutimun Chanmuang N. ${ }^{5}$, Ty J. Prosa ${ }^{2}$, David J. Larson ${ }^{2}$, John W. Valley ${ }^{1}$

${ }^{1}$ Department of Geoscience, University of Wisconsin - Madison, Madison, WI, USA.

${ }^{2}$ CAMECA Instruments, Inc., Madison, WI, USA

${ }^{3}$ Department of Geological Sciences, Stanford University, Stanford, CA, USA

${ }^{4}$ School of Earth and Planetary Science, Curtin University, Perth, WA, Australia

${ }^{5}$ Institut für Mineralogie und Krystallographie, Universitat Wien, Wien, Austria.

* Corresponding Author: tbblum@geology.wisc.edu

Lunar and terrestrial zircon grains record the early evolution of the Earth-Moon system, and by association, dynamic processes within the early inner solar system. Zircon dates, which provide a lower limit on the age of the Moon [1], can be combined with zircon trace elements and isotope ratios to better understand the initiation, duration, spatial extent and composition of lunar magmatism [2-4]. While zircon remains one of the most robust phases for studying the Moon, debate persists concerning the magnitude, prevalence, and driving forces for $\mathrm{Pb}$ mobility in the lunar environment [5].

Atom probe tomography (APT) represents a novel means to characterize elemental and isotopic compositions of minerals on the scale of tens of nanometers. In terrestrial zircons, nanoscale clustering of $\mathrm{Pb}$ within single zircons has been linked to transient thermal episodes. When combined with micronscale $\mathrm{U}-\mathrm{Pb}$ analysis from secondary ion mass spectrometry (SIMS), $\mathrm{Pb}$ isotopes in nano-clusters record the timing of Pb clustering [7,8]. This work applies APT and SIMS to the study of zircon 17B-4, an isolated zircon within the matrix of lunar sample 73235,87 . Sample 73235 is a clast-rich aphanitic breccia collected from "light mantle" material on the south side of the Taurus-Littrow Valley during Apollo 17 [9]. The light mantle material is interpreted as landslide deposits from the adjacent South Massif [9,10], and the ${ }^{40} \mathrm{Ar} /{ }^{39} \mathrm{Ar}$ plateau age of $3946 \pm 95 \mathrm{Ma}(2 \sigma)$ of the breccia matrix [11] (here recalculated using modern decay constants and monitor mineral ages) and has been interpreted to reflect the timing of the Serenitatis basin-forming impact.

SIMS U-Pb analyses on $17 \mathrm{~B}-4$ yield ${ }^{207} \mathrm{~Pb} /{ }^{206} \mathrm{~Pb}$ ages between $4338 \pm 12$ and $4392 \pm 12 \mathrm{Ma}(2 \sigma)$; the oldest and most concordant U-Pb analysis (4392 $\pm 12 \mathrm{Ma}$, 99\% concordant) is interpreted to reflect primary crystallization. The [U] and [Th] range from 156-200 $\mu \mathrm{g} / \mathrm{g}$ and $81-115 \mu \mathrm{g} / \mathrm{g}$, respectively. A series of needle-shaped specimens for APT analysis were prepared from a single FIB (focused ion beam) lift-out taken adjacent to the oldest SIMS analysis (Fig. 1). APT data sets contain a small number of $\mathrm{Pb}$-rich clusters, between $5-10 \mathrm{~nm}$ in diameter. The ${ }^{207} \mathrm{~Pb} /{ }^{206} \mathrm{~Pb}$ ratio within individual clusters are statistically identical, with a combined ratio of $1.42 \pm 0.07$. Using a simple clustering model $[7,8]$, this places $\mathrm{Pb}$ cluster formation at $3850+150 /-170 \mathrm{Ma}(2 \sigma)$. This cluster formation age overlaps the ${ }^{40} \mathrm{Ar} /{ }^{39} \mathrm{Ar}$ age for the host breccia, and links cluster formation to the Serenitatis impact event.

The in-depth characterization of zircon 17B-4 provides a high degree of confidence that the ${ }^{207} \mathrm{~Pb} /{ }^{206} \mathrm{~Pb}$ age of $4392 \pm 12$ Ma records primary crystallization, making 17B-4 one of the oldest reliably dated lunar zircons. APT data document the first known occurrence of nanoscale Pb clustering in lunar zircon, 
and the first ever correlation of $\mathrm{Pb}$ clustering to impact processes. This multi-scale characterization of $\mathrm{U}-$ $\mathrm{Pb}$ systematics represents a novel means to study magmatic and impact processes during early lunar evolution.

References:

[1] AA Nemchin et al., Nature Geoscience 2 (2009) p. 133-136.

[2] C Meyer et al., Meteoritics and Planetary Science 31 (1996) p. 370-387.

[3] AA Nemchin et al., Geochimica et Cosmochimica Acta 72 (2008) p. 668-689.

[4] JW Valley et al., Contributions to Mineralogy and Petrology 167 (2014) p. 956.

[5] AJ Cavosie et al., Geology 43 (2015) p. 999-1002.

[7] JW Valley et al., Nature Geoscience 7 (2014) p. 219-223.

[8] TB Blum et al., in "Microstructural Geochronology: Planetary Records Down to Atomic Scale", ed.

DE Moser et al., (John Wiley \& Sons, Hoboken, NJ) p. 327-349.

[9] EW Wolfe et al., U.S. Geological Survey Professional Paper 1080 (1981).

[10] D Hurwitz and DA Kring, Earth and Planetary Science Letters 436 (2016) p. 64-70.

[11] G Turner and PH Cadogan, Proc. $6^{\text {th }}$ Lunar Sci Conference (1975) p. 1509-1538.
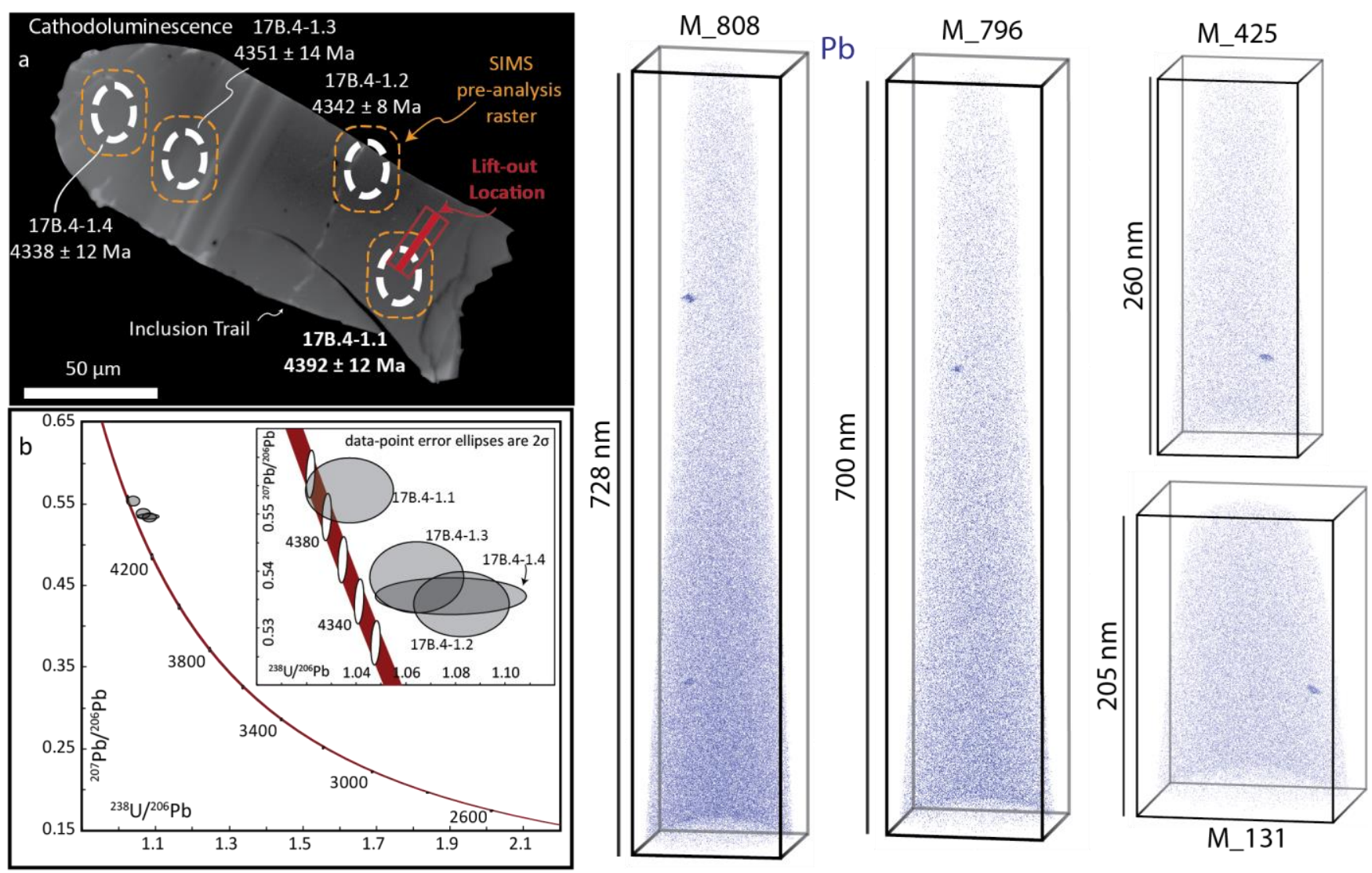

Figure 1: Summary of SIMS U-Pb data, and Pb distributions from APT analyses. (a) Cathodoluminescence image of zircon 17B-4 showing the location of SHRIMP U-Pb analyses, and ${ }^{207} \mathrm{~Pb} /{ }^{206} \mathrm{~Pb}$ ages. (b) Tera-Wasserburg diagram for SHRIMP U-Pb data. (On right): reconstructed APT data sets showing the distribution of individual $\mathrm{Pb}$ atoms. 